Aim of the study: The treatment for papillary thyroid microcarcinoma (PTMC), which is a tumor measuring less than $1 \mathrm{~cm}$, is still a subject of controversy. The aim of this study is to retrospectively evaluate the patients diagnosed with PTMC in terms of their clinical and histopathological features.

Material and methods: A total of 153 consecutive patients with PTMC were treated, and their clinical and histopathological characteristics were reviewed. The tumor diameter was observed to range from $1.0 \mathrm{~mm}$ to $10 \mathrm{~mm}$ (mean of $5.8 \mathrm{~mm}$ ). Histologically, 138 (90.2\%) cases of classical papillary carcinoma and 15 (9.8\%) cases of the follicular variant were noted. Multicentric tumors were found in 37 (24.2\%) patients, of whom 12 (7.8\%) had more than one PTMC on the same side and 25 (16.3\%) displayed bilateral PTMC. Results: The proportions of capsular invasion and lymph node metastasis were $11.8 \%$ (18/153) and 48.1\% (39/81), respectively. One patient showed distant metastasis during follow-up and died fifteen months after the operation. PTMC showed a high incidence of multifocality and lymph node metastasis in the level VI central compartment. The optimal surgical strategy for PTMC was total thyroidectomy and central compartment node dissection.

Conclusions: Frozen tissue sections should be made for the prompt diagnosis of PTMC in all the thyroid nodules, except when the malignant diagnosis was already confirmed by cytology.

Key words: papillary thyroid microcarcinoma (PTMC), frozen section (FS), treatment.

\section{Treatment for papillary thyroid microcarcinoma}

Lan Shi' ${ }^{1}$ Jun-hua Chen ${ }^{2}$, Shun-tao Wang ${ }^{1}$, Yi-quan Xiong ${ }^{1}$, Tao Huang ${ }^{3}$

\author{
${ }^{1}$ Breast \& Thyroid Surgery Center, Union Hospital, Tongji Medical College, \\ Huazhong University of Science and Technology, Wuhan, China \\ 2Department of General Surgery, Union Hospital, Tongji Medical College, \\ Huazhong University of Science and Technology, Wuhan, China \\ 3Union Hospital, Tongji Medical College, Huazhong University of Science \\ and Technology, China
}

\section{Introduction}

Papillary thyroid microcarcinoma (PTMC) is a specific subgroup of papillary thyroid carcinoma, which according to the World Health Organization measures $10 \mathrm{~mm}$ or less. The incidence of thyroid cancers, particularly of PTMC, has been sharply increasing in Western countries for several years [1]. The relative rate of PTMC has increased in patients with differentiated thyroid carcinoma mainly because of (1) the improvements in the diagnostic instruments [high-resolution ultrasonography, fine-needle aspiration cytology (FNA cytology), computed tomography (CT) scan, magnetic resonance imaging (MRI) and their frequent use, as well as [2] the accurate pathological examination of thin slices of specimens.

A large proportion of these tumors were found incidentally during the treatment of benign thyroid diseases, and most cases followed an indolent course with an excellent prognosis [2]. However, more aggressive behavior with regional and distant metastasis did occur [3]. Different therapeutic approaches to PTMC are available, and these vary from the radical total thyroidectomy followed by ${ }^{131}$ | ablation to the more conservative lobectomy with or without isthmectomy. Close observation with non-surgical follow-up has also been introduced. However, debates have centered on the optimal therapy offered to PTMC patients [3-6].

The therapeutic strategy of choice should be closely associated with the clinical and pathological features of PTMC. The present study will retrospectively summarize the clinical and histopathological characteristics of 153 PTMC patients and will attempt to derive from the analysis a rationale for the appropriate diagnostic and therapeutic interventions.

\section{Material and methods}

Between June 2003 and December 2008, 153 patients with PTMC were operated on consecutively at the Breast and Thyroid Surgical Department of the Union Hospital, Tongji Medical College, Huazhong University of Science and Technology, Wuhan, China. This study was conducted in accordance with the Declaration of Helsinki. This study was conducted with approval from the Ethics Committee of Tongji Medical College. Written informed consent was obtained from all participants.

These patients were a subset of a series of 1087 different thyroid cancer patients treated in this surgical center during the said time period. Of the 153 patients, 136 were females (88.9\%) and 17 were males (11.1\%), with a female to male ratio of 8:1. The mean age at the time of operation was 45.9 years (range, 19-80 years); 71 patients (46.4\%) were $<45$ years of age, and 82 patients (53.6\%) were $\geq 45$ years of age. The prominent nodule of multinodular goiter or the 
solitary nodule was sampled through FNA biopsy in 57 (37.3\%) of the patients during pre-operation. The cytological findings of the FNA were classified as follows: (1) benign (40, 70.2\%); (2) suspicious (6, 10.5\%); and (3) malignant (11, 19.3\%). Out of the 11 confirmed malignant cases, the five with clinically palpable laterocervical masses were sampled through FNA in the laterocervical node and were diagnosed with nodal metastases. A total of 142 patients underwent frozen-section (FS) biopsy. FS biopsy results showed malignant disease in 129 patients (90.8\%), and were deferred in 13 patients (9.2\%) diagnosed through post-operative pathology examination. A total of 19 patients (12.4\%) had thyroid dysfunction, 7 and 12 of whom had hyperthyroidism and hypothyroidism, respectively. All patients with PTMC in our department were treated with total thyroidectomy, including 12 patients for reoperation. Central and laterocervical compartment cervical lymph node dissection were deployed in 81 and 35 cases, respectively. The mean follow-up after the first treatment was at 20 months (range, 6-66 months). The follow-up consisted of a clinical examination, measurement of the serum thyroglobulin and anti-thyroglobulin levels, and neck highresolution ultrasonography. Whole-body scans were taken five to six days after ${ }^{131} \mid$ radiotherapy, or whenever appropriate. A total of 45 patients were followed up with ${ }^{131}$ | treatment because of multifocality, extrathyroidal invasion, and nodal metastases. One patient received internal and external irradiation for the extensive invasion of local lymph nodes. All patients received TSH-suppressive doses of L-thyroxine during the subsequent follow-up.

\section{Results}

The mean primary tumor size was $5.8 \mathrm{~mm}$ (range, 1.0$10 \mathrm{~mm}$ ). In 116 patients (75.8\%), a single focus of PTMC was found, whereas 37 (24.2\%) patients had multifocal PTMC, $12(7.8 \%)$ of whom had multiple tumor foci in one thyroid lobe only, and 25 (16.3\%) had foci in both lobes. The pathological examination of the PTMC identified the papillary histotype in 138 patients (90.2\%) and the follicular variant in 15 patients (9.8\%). In 6 patients (3.9\%), a peritumoral sclerotic capsule was observed. Thirteen cases (9.2\%) that underwent intraoperative FS, 8 of which were papillary cases and 5 were of follicular variant histotype, failed to be diagnosed and confirmed by postoperative paraffin sections. Extracapsular thyroid invasion was found in 18 patients (11.8\%). Among the 81 patients associated with central compartment cervical lymph node dissection, lymph node metastases were found in 39 cases (48.1\%). A total of 35 patients with lymph node metastases were diagnosed or suspected pre-operatively through nodal cytology or ultrasonography. Modified radical neck dissection was deployed, including the laterocervical compartment of the neck; ten positive cases were identified (28.6\%). Table 1 shows the clinical, diagnostic, therapeutic, and histopathological characteristics of the patient population. Twelve patients were reoperated on within six months after postoperative malignant pathology examinations that raised uncertainties about the remaining thyroid tissue; only two patients were found to have residual micropapillary cancer tissue. During the subsequent followup, one 74-year-old patient was found to have lung metasta- sis five months after total thyroidectomy and palliative lymph node dissection for extensive lymph node invasion. Although the operation was followed by ${ }^{131}$ | radiotherapy once and by external irradiation twice, the said patient died of lung metastasis fifteen months after the operation. Meanwhile, none of the other patients showed any signs of recurrence or metastasis.

Co-existing multinodular goiter was found in 91 patients (59.5\%), Hashimoto's disease in 29 patients (19.0\%), follicular or Hürthle cell adenoma in 5 patients (3.3\%), and Graves' disease in 2 patients (1.3\%).

After surgery, 52 cases of transient hypocalcemia and 2 cases of transient larynx nerve palsy were observed, but no cases of permanent larynx nerve palsy or hypoparathyroidism were noted.

\section{Discussion}

PTMC has been defined to have foci measuring up to a maximum of $10 \mathrm{~mm}$ in diameter, and accounts for up to $30 \%$ of all papillary thyroid cancers $[4,7]$. Although various therapeutic approaches to PTMC are applied in clinical practice, the optimal therapeutic strategy for PTMC remains controversial.

Most surgeons prefer to confirm all diagnoses of neoplasia using FNA biopsy or intraoperative FS examination, and to guide the extent of the thyroidectomy. The most cost-effective test for evaluating thyroid masses is the FNA biopsy, the accuracy of which exceeds $80 \%$ in most series [8]. However, occult carcinomas are difficult to diagnose using FAN, and some recommend the use of ultrasound-guided FNA biopsy [9]. For the series in the present study, the sensitivities of FNA and intraoperative FS in thyroid cancer patients were

Table 1. Clinical profile, pathology, operative procedures and complications of PTMC patients $(n=153)$

\begin{tabular}{|c|c|}
\hline Patients & \\
\hline $\begin{array}{l}\text { Mean age (range) } \\
\text { Female/male }\end{array}$ & $\begin{array}{c}45.9(19-80) \\
136 / 17\end{array}$ \\
\hline $\begin{array}{l}\text { Diagnose } \\
\text { FNA (positive N. / total N.) } \\
\text { FS (positive N. / total N.) }\end{array}$ & $\begin{array}{c}11 / 57(19.3 \%) \\
129 / 142(90.8 \%)\end{array}$ \\
\hline $\begin{array}{l}\text { Pathology } \\
\text { Mean tumor size }\end{array}$ & $5.8 \mathrm{~mm}$ \\
\hline $\begin{array}{l}\text { Number of foci } \\
\text { Single } \\
\text { Unilaterally multifocal } \\
\text { Bilaterally multifocal } \\
\text { Papillary carcinoma } \\
\text { Follicular variant }\end{array}$ & $\begin{array}{c}116(75.8 \%) \\
12(5.9 \%) \\
25(16.5 \%) \\
138(90.2 \%) \\
15(9.8 \%)\end{array}$ \\
\hline $\begin{array}{l}\text { Management } \\
\text { Total thyroidectomy }\left(1^{\text {st }} / 2^{\text {nd }}\right)\end{array}$ & $141 / 12$ \\
\hline $\begin{array}{l}\text { Associated lymph node dissection } \\
\text { Central compartment (positive N./total N.) } \\
\text { Laterocervical compartment (positive N./total N.) }\end{array}$ & $\begin{array}{l}39 / 81(48.1 \%) \\
10 / 35(28.6 \%)\end{array}$ \\
\hline $\begin{array}{l}\text { Complications } \\
\text { Temporary hypocalcemia } \\
\text { Temporary RLN palsy }\end{array}$ & $\begin{array}{c}52 \\
2\end{array}$ \\
\hline
\end{tabular}

$R L N$ - recurrent laryngeal nerve. 
19.3\% (11/57) and 90.8\% (129/142), respectively. Some researchers have opined that ultrasound-guided FNA biopsy could improve the diagnosis of PTMC $[9,10]$. However, controversies concerning the role of FS have been a matter of debate [11], with the differing views resulting from the various experiences during sampling. An accurate pathological examination of very thin slices of specimens is very important. More attention should be given to foci with the following characteristics: very hard isolated nodes, grayish-white incisal surfaces with pyknosis of the parenchyma, radial scarlike tissue, tiny psammoma bodies, and signs of capsular cells gathering together. The FS diagnosis was deferred for 13 cases (8 cases of papillary histotype, 3 cases of the follicular variant, and 2 cases of follicular carcinoma), which were difficult to diagnose through FNA and FS [12]. Despite the limitations, the results of this study rejected the idea that FS is no longer useful for diagnosing PTMC. We recommend the use of routine FS biopsy in the operative assessment of thyroid nodules. Omitting FS should only be suggested for cases when FNA can reveal PTMC malignancy.

At present, PTMC has two categories. First, in the low-risk group of PTMC, the tumors behave more like benign lesions that are slow-growing and have no clinical symptoms. Without any lymph node metastasis and blood vessel invasion, these microcarcinomas are always detected incidentally in surgical specimens of benign thyroid diseases and have a favorable prognosis. This group should be monitored and observed periodically, but does not need to be actively treated until the tumors display more aggressive characteristics. Ito et al. [4] reported that in $70 \%$ of 162 microcarcinoma patients under observation, the tumor size decreased or did not change at each follow-up. A recent observation trial [13] showed that only $6.7 \%$ of low-risk PTMC definitely became enlarged during the five years of follow-up. These results and the high incidence of PTMC detected in autopsy studies [2] indicated that observation was an attractive alternative to surgery for this group. Meanwhile, the second group of high-risk PTMC is recognized through the histological changes in tumor regression, such as tall-celled diffuse sclerosing variants, or multicentric foci and their follicular variants. This group exhibits unfavorable outcomes associated with clinically evident nodal metastasis, extrathyroidal invasion, and/or distant metastasis. This group is most likely to recur and exhibit worse prognosis compared with the lowrisk group. Total thyroidectomy and careful therapeutic neck dissection followed by 131 ablation therapy are required [1417]. Classifying patients with PTMC into high-risk and lowrisk groups is important when determining the treatment method. Although Ardito [16] has reported that aggressive behavior of PTMC strongly correlated with some histopathological features (extrathyroid invasion, solid pattern, tumor multifocality, and absence of a capsule), the lack of strong evidence to anticipate the course and long-term outcome for PTMC patients, particularly in predictive parameters, remains contentious $[16,17]$. Given the high incidence of bilateral tumors in PTMC [17-19], total thyroidectomy is often the judicious choice [20, 21]. By contrast, Dietlein et al. [22] reported that subtotal thyroidectomy combined with radioiodine ablation was enough for incidental multifocal PTMC.
Routine therapeutic lymph node dissection at the time of thyroidectomy is warranted in patients with papillary microcarcinoma having palpable lymph nodes at presentation. However, the effect of prophylactic lymph node dissection on patients without palpable lymphadenopathy has been disputed [23]. Cappelli et al. [24] found that the prevalence of nodal involvement that develops during the follow-up period was significantly higher in PTMC than in papillary thyroid cancer. Simpson et al. [25] reported two cases of PTMC that both measured less than $1.5 \mathrm{~mm}$ with regional lymph node metastasis and with histological features of regression. In our series, the smallest primary tumor with regional lymph node metastasis was $2 \mathrm{~mm}$, and the percentage of central compartment lymph node metastasis was 48.1\% (39/81). Some researchers reported that the central compartment lymph node metastasis of PTMC is very high, and routine central neck dissection is recommended [26, 27]. Lymph node metastasis also has a significant association with capsule invasion, extracapsular invasion, palpable lymphadenopathy, and tumor size $[19,28]$. Pakdaman et al. [29] proposed that PTMCs that were larger than or equal to $4 \mathrm{~mm}$ had an increased risk of extrathyroidal spreading. From our analysis, we recommend prophylactic central compartment dissection at the time of thyroidectomy. This recommendation is in line with a previous report [26, 27], despite the fact that some researchers reported that the presence of central node metastasis is unrelated to the disease-free survival rate of PTMC patients [30].

Routine prophylactic laterocervical lymph node dissection was previously thought to be excessive treatment. However, PTMC can metastasize into cervical nodes, as seen from our clinical data, wherein 3.3\% (5/153) of the patients had primary symptoms of the disease in the form of clinically palpable laterocervical masses. Chung et al. [31] found that "skip metastasis," which is defined as lateral lymph node metastasis without central lymph node metastasis, also occurred in $7.7 \%$ of patients with PTMC. Therefore, we recommend a modified neck dissection if palpable lymph node metastases are present in the jugulo-carotid chain. Otherwise, preoperative ultrasonography or computed tomography should be used when lateral node metastasis is suspected.

In conclusion, our study demonstrated that PTMC has a significant rate of bilateral tumors and lymph node metastases. Routine FS biopsy during operation increased the chances of finding PTMC. Omitting FS is suggested only in cases where FNA can reveal malignancy. Performing total thyroidectomy and central compartment dissection at the time of diagnosis and avoiding the need for an additional surgical procedure are preferable. Laterocervical compartment dissection should be performed when lateral lymph node metastasis is confirmed or suspected.

\section{References}

1. Jemal A, Siegel R, Ward E, Hao Y, Xu J, Murray T, Thun MJ. Cancer statistics, 2008. CA Cancer J Clin 2008; 58: 71-96.

2. de Matos PS, Ferreira AP, Ward LS. Prevalence of papillary microcarcinoma of the thyroid in Brazilian autopsy and surgical series. Endocr Pathol 2006; 17: 165-73.

3. Arora N, Turbendian HK, Kato MA, Moo TA, Zarnegar R, Fahey TJ 3rd. Papillary thyroid carcinoma and microcarcinoma: is there a need to distinguish the two? Thyroid 2009; 19: 473-7. 
4. Ito Y, Tomoda C, Uruno T, et al. Papillary microcarcinoma of the thy roid: how should it be treated? World J Surg 2004; 28: 1115-21.

5. Yu XM, Wan Y, Sippel RS, Chen H. Should all papillary thyroid microcarcinomas be aggressively treated? An analysis of 18,445 cases. Ann Surg 2011; 254: 653-60.

6. Hyun SM, Song HY, Kim SY, Nam SY, Roh JL, Han MW, Choi SH. Impact of combined prophylactic unilateral central neck dissection and hemithyroidectomy in patients with papillary thyroid microcarcinoma. Ann Surg Oncol 2012; 19: 591-6.

7. Sorrentino F, Atzeni J, Romano G, Buscemi G, Romano M. Differentiated microcarcinoma of the thyroid gland. G Chir 2010; 31: 277-8.

8. Shaha AR, DiMaio T, Webber C, Jaffe BM. Intraoperative decision mak ing during thyroid surgery based on the results of preoperative needle biopsy and frozen section. Surgery 1990; 108: 964-7.

9. Yang GC, LiVolsi VA, Baloch ZW. Thyroid microcarcinoma: fine-needle aspiration diagnosis and histologic follow-up. Int J Surg Patho 2002; 10: 133-9.

10. Nam-Goong IS, Kim HY, Gong G, Lee HK, Hong SJ, Kim WB, Shong YK. Ultrasonography-guided fine-needle aspiration of thyroid incidentaloma: correlation with pathological findings. Clin Endocrinol (Oxf) 2004; 60: 21-8.

11. Makay O, Icoz G, Gurcu B, Ertan Y, Tuncyurek M, Akyildiz M, Yetkin E. The ongoing debate in thyroid surgery: should frozen section analysis be omitted? Endocr J 2007; 54: 385-90.

12. Lin HS, Komisar A, Opher E, Blaugrund SM. Follicular variant of papillary carcinoma: the diagnostic limitations of preoperative fine-needle aspiration and intraoperative frozen section evaluation. Laryngoscope 2000; 110: 1431-6.

13. Ito Y, Miyauchi A. A therapeutic strategy for incidentally detected pap illary microcarcinoma of the thyroid. Nat Clin Pract Endocrinol Metab 2007; 3: 240-8

14. Giordano D, Gradoni P, Oretti G, Molina E, Ferri T. Treatment and prognostic factors of papillary thyroid microcarcinoma. Clin Otolaryngol 2010; 35: 118-24.

15. Abboud B, Daher R, Sleilaty G, Abadjian G, Ghorra C. Are papillary microcarcinomas of the thyroid gland revealed by cervical adenopathy more aggressive? Am Surg 2010; 76: 306-11.

16. Ardito G, Revelli L, Giustozzi E, et al. Aggressive papillary thyroid microcarcinoma: prognostic factors and therapeutic strategy. Clin Nucl Med 2013; 38: 25-8.

17. Pelizzo MR, Boschin IM, Toniato A, Piotto A, Bernante P, Pagetta C, Rampin L, Rubello D. Papillary thyroid microcarcinoma (PTMC): prognostic factors, management and outcome in 403 patients. Eur J Surg Oncol 2006; 32: 1144-8

18. Connor MP, Wells D, Schmalbach CE. Variables predictive of bilat eral occult papillary microcarcinoma following total thyroidectomy. Otolaryngol Head Neck Surg 2011; 144: 210-5

19. Vasileiadis I, Karakostas E, Charitoudis G, Stavrianaki A, Kapetanakis S, Kouraklis G, Karatzas T. Papillary thyroid microcarcinoma: clinicopathological characteristics and implications for treatment in 276 patients. Eur J Clin Invest 2012; 42: 657-64.

20. Ciuni R, Musmeci N, Di Giunta M, Basile F, Ciuni S. Treatment of microcarcinoma and papillary carcinoma of the thyroid. Ann Ital Chir 2010; 81: 115-9.

21. Koo BS, Lim HS, Lim YC, Yoon YH, Kim YM, Park YH, Rha KS. Occult contralateral carcinoma in patients with unilateral papillary thyroid microcarcinoma. Ann Surg Oncol 2010; 17: 1101-5.

22. Dietlein M, Luyken WA, Schicha H, Larena-Avellaneda A. Incidental multifocal papillary microcarcinomas of the thyroid: is subtotal thy roidectomy combined with radioiodine ablation enough? Nucl Med Commun 2005; 26: 3-8

23. Ito Y, Higashiyama T, Takamura Y, Miya A, Kobayashi K, Matsuzuka F, Kuma K, Miyauchi A. Prognosis of patients with benign thyroid diseases accompanied by incidental papillary carcinoma undetectable on preoperative imaging tests. World J Surg 2007; 31: 1672-6.

24. Cappelli C, Castellano M, Braga M, Gandossi E, Pirola I, De Martino E, Agosti B, Rosei EA. Aggressiveness and outcome of papillary thyroid carcinoma (PTC) versus microcarcinoma (PMC): A mono-insti tutional experience. J Surg Oncol 2007; 95: 555-60.

25. Simpson KW, Albores-Saavedra J. Unusual findings in papillary thyroid microcarcinoma suggesting partial regression: a study of two cases. Ann Diagn Pathol 2007; 11: 97-102.
26. So YK, Seo MY, Son YI. Prophylactic central lymph node dissection for clinically node-negative papillary thyroid microcarcinoma: influence on serum thyroglobulin level, recurrence rate, and postoperative complications. Surgery 2012; 151: 192-8.

27. So YK, Son YI, Hong SD, Seo MY, Baek CH, Jeong HS, Chung MK. Subclinical lymph node metastasis in papillary thyroid microcarcinoma: a study of 551 resections. Surgery 2010; 148: 526-31.

28. Zhang L, Wei WJ, Ji QH, et al. Risk factors for neck nodal metastasis in papillary thyroid microcarcinoma: a study of 1066 patients. J Clin Endocrinol Metab 2012; 97: 1250-7.

29. Pakdaman MN, Rochon L, Gologan O, Tamilia M, Garfield N, Hier MP, Black MJ, Payne RJ. Incidence and histopathological behavior of papillary microcarcinomas: study of 429 cases. Otolaryngol Head Neck Surg 2008; 139: 718-22.

30. Ito $Y$, Tomoda C, Uruno T, et al. Clinical significance of metastasis to the central compartment from papillary microcarcinoma of the thyroid. World J Surg 2006; 30: 91-9.

31. Chung YS, Kim JY, Bae JS, et al. Lateral lymph node metastasis in papillary thyroid carcinoma: results of therapeutic lymph node dissection. Thyroid 2009; 19: 241-6.

\section{Address for correspondence}

\section{Prof. Tao Huang}

Union Hospital

Tongji Medical College

Huazhong University of Science and Technology

No.1277 Jiefang Road

430022 Wuhan, China

e-mail: shuiguanbao@163.com

Submitted: $\quad$ 14.07.2012

Accepted: 21.01.2013 